\title{
Regional learning networks - building bridges between schools, university and community
}

\author{
Andreas Breiter \\ Telecommunications Research Group, University of Bremen, P.O. Box 330 440, 28334 Bremen, \\ Germany
}

abreiter@informatik.uni-bremen.de

Key words: Digital Divide, Equity, Lifelong Learning/Education, Partnership

\begin{abstract}
The so-called "digital divide" seems to be a major social obstacle for the Information Society. Most experts agree that citizens will need competencies that go beyond the basic cultural skills. Where can our citizens acquire these competencies? The idea of life-long-learning illustrates a major problem of our educational institutions: they work separately, they only process the results of the preceding phase and there is a lack of interconnection. This paper tries to develop a concept of a regional education network that includes pre-school, $\mathrm{K}$ 12 and further education, public libraries and community centres as well as other educational institutions. Taking the path of the digital divide as a social and educational divide and focusing on the school as one major player in the regional network, the innovation process and the actors involved in it are highlighted and explored. Using action research in a project between schools, local community, private partners and the university, the concept of the regional network is illustrated. The problems encountered in the project are described and discussed in order to give a realistic overview and impression of an integrated education policy.
\end{abstract}

\section{THE DIGITAL DIVIDE AS A CHALLENGE FOR EDUCATION POLICY}

Most experts agree that the Internet will fundamentally change the way

The original version of this chapter was revised: The copyright line was incorrect. This has been corrected. The Erratum to this chapter is available at DOI: 10.1007/978-0-387-35663-1_34 
we live and work and the way we communicate in private and in public. Business processes within and between companies will change and so will public administration and political decision-making processes. Today, nobody is able to say with certainty what changes will take place but it is obvious that with increasing competition, organizations and individuals who understand the new digital media and are able to use it for their own purposes will gain certain advantages.

It is debatable whether the competent use of the various Internet services really is a cultural skill to be compared with reading and writing. Without doubt the World Wide Web as a complex, distributed information resource can only be used effectively with the competence formerly found in specialized jobs such as information brokers, librarians, documentation experts or journalists - which can now be carried out in do-it-yourself style. However, just as nobody necessarily becomes a good craftsman when a DIY store opens, the availability of websites and search engines does not mean that people will use them competently to reach their goals. Hence, teaching and learning media literacy is at the top of the agenda of education policy. Equipping schools and universities with computers and Internet connections is massively supported, leaving decreasing budgets for other aspects of educational provision.

However, schools only serve just over a bit more than 10 per cent of the overall population. Recently, a representative study found that nearly half of the German population are Internet 'objectors' (TSN-Emnid 2001). This notion suggests that these people had thoroughly investigated the Internet and had come to the conclusion that there is nothing relevant for them. Obviously, this is not the case: they have no experience and normally they will not buy a computer to find out the opposite. There are people who master the challenge and learn to use the new digital medium with more or less help from their personal or work environment. After all, about 40 per cent of Germans have Internet access and in other countries the proportion is even higher.

Closer examination of the socio-demographic distribution of Internet users reveals a divide between the groups in respect of their educational backgrounds. Ten times more people with a university degree are using the Internet than people without a high school degree. Therefore, those with a good education are expanding their leading position by using the new medium, while the disadvantaged are further falling behind. This can become a vicious circle because you can only learn to use the medium if you are able to master certain cultural skills, especially reading. This means that the digital divide does not create a new segregation, but it is increasing the existing educational differences. Among 80 million Germans, 16 million work at home, 4 million are unemployed and more than 20 million are older 
citizens. Beside initiatives like 'Schulen ans Netz' there are now initiatives in state institutions for special user groups, in public libraries, adult education centres, Community Technology Centres and youth centres as well as in commercial Internet cafés.

\section{THE LEARNING EFFECTIVENESS PARADOX IN SCHOOLS}

The ultimate goal of computer and Internet use in schools is better teaching and learning - usually measured by student achievement in standardized tests. According to studies on learning effectiveness in the last decade there is no hard evidence that the use of digital media for learning is more effective than traditional methods. Some studies found an increase in students' and teachers' motivation (Bertelsmann 1997), other studies noted ambivalent results in achievement tests (Wenglinsky 1998) depending on the way digital media were introduced into the curriculum (for an excellent overview see (Kulik 1994)).

Although there is a lack of empirical evidence, politicians, industry and foundations put billions of Euros into hard- and software, telecommunication infrastructure, curriculum development and teacher training. This can be called the 'learning effectiveness paradox'. It is derived from the well known 'productivity paradox' described in Information Systems literature - despite the heavy investment in IT in companies, productivity is not increasing or at least is hard to measure (Brynjolfsson and Hitt 1996).

What are the educational deductions from the 'learning effectiveness paradox'? If one argues economically, then any further investment in digital media in schools is wrong - the traditionalists argue for more teachers and less media. On the other hand, as we know from other organizations, media are experience goods that develop their value through usage and all organizations go through a learning process. In order to describe the interdependence of technology diffusion and organizational learning, different phase models have been proposed (Nolan 1993). What they have in common is that they outline a transition from an uncoordinated start phase to a targeted phase of steering and integration of technology into working processes and organizational structures (Figure 1). Technology has to be embedded in organizational processes again and again, and new structures and processes have to be created.

If we look into the process in schools and other educational institutions, this description highlights a lot of similarities. This combination of organizational learning and the integration of educational technologies was perfectly described by the study of RAND Co. for the U.S. Department of 
Education which concluded: "Technology without reform is likely to have little value; widespread reform without technology is probably impossible" (Glennan and Melmed 1996).

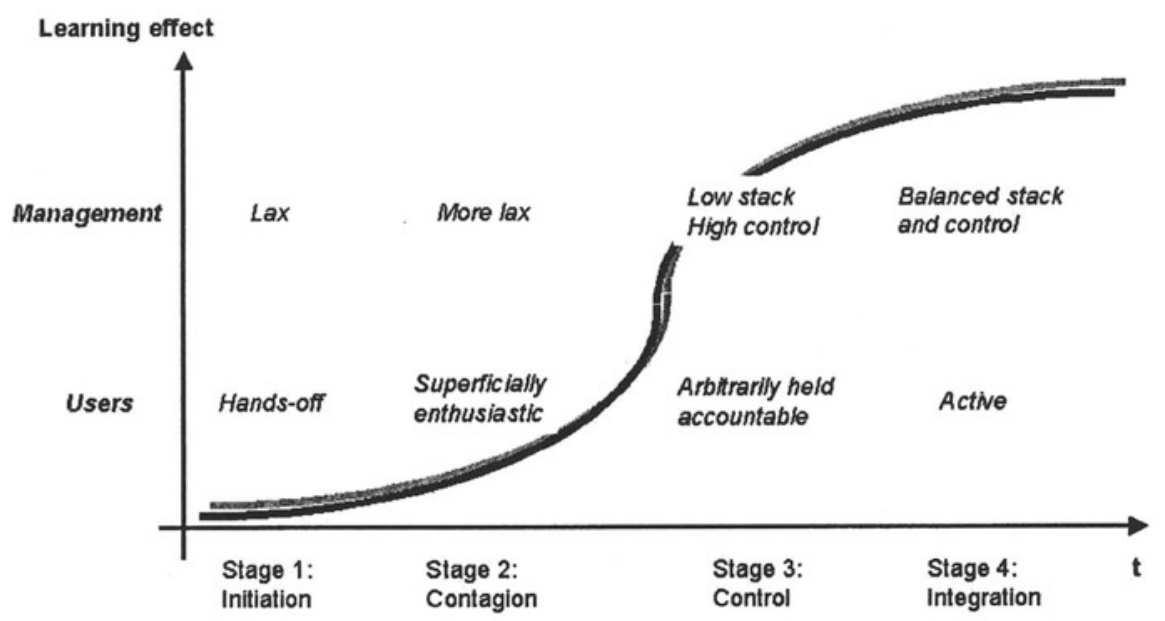

Figure 1. Development phases of IT use in organisations

After the eruption caused by the PISA study (Programme of International Student Assessment) the role of teaching and learning returned to the focus of politics, practice and research. This has considerable relevance for the use of digital media in schools. In an analysis, the North Central Regional Educational Laboratory (NCREL) described the ideal type of "engaged learning" (North Central 1997) and maintained it was built on the following basic principles:

- Children are engaged in authentic and multidisciplinary tasks.

- Assessments are based on students' performance of real tasks.

- Students participate in interactive modes of instruction.

- Students work collaboratively.

- Students are grouped heterogeneously.

- Students learn through exploration.

- Teachers are facilitators in learning.

One project to support authentic learning and provide a good combination of school-based activities with the local community to combat the digital divide has been set up in the State of Bremen. 


\section{THE WEBPOINTS}

Using action research as a method is fairly new in information systems research. There are numerous definitions, however one of the most widely cited is that of Rapoport's. He defines the aims of action research "to contribute both to the practical concerns of people in an immediate problematic situation and to the goals of social science by joint collaboration within a mutually acceptable ethical framework" (Rapoport 1970). Action research focuses on collaborative aspects and possible ethical dilemmas that might result from its use. It is a valid research method in fields such as organizational development and education. However, in information systems, there seems to be increasing interest in action research although it was largely ignored for a long time (Baskerville and Wood-Harper 1998). In this paper, action research is used as an interpretative methodology to construct the basis of a formative evaluation, i.e. to learn from experience in the organization development process.

Most German Laender have enacted in their Education Laws that schools should open towards the local community. The school is part of public life and, as such, should play a major role in life-long-learning together with other education institutions. In Bremen, this gap between schools and their local communities might be partly filled by the project 'Webpoints'. The author was leader of a project team, managing the implementation process. This public-private-partnership between the State of Bremen and German Telecom has invested about 2 million Euros over two years (2000-2002) to build up Internet-Cafés in 25 schools in Bremen and Bremerhaven. The new computer labs provided in the schools can be used for teaching and learning in the morning hours, in the afternoon they are open to the public. The aim is to give schools the opportunity to establish partnerships with the local community via the medium of the computer. The key aspect of the concept is the support of external users by students of the schools - the 'webscouts'. They are given training in the basic technical skills and in instructing by university students. The webscouts give external users advice in how to find websites, how to install a personal e-mail account, how to use a spreadsheet or how to print out a text. This brings a double effect: university students in education get field experience and a new feeling in how to deal with kids. The webscouts develop important skills - technical know-how and especially the acquisition of social competencies in dealing with lay users.

The schools had to go through a difficult application procedure before they were accepted onto the project. This was new to them. An external committee at the University judged their applications according to several criteria:

- Quality of concept and IT-plan. 
- Location (schools from disadvantaged regions with better chances).

- Quality of the room (free, separate, external access).

- Opening hours (5 hours a day from $2 \mathrm{pm}$ to $7 \mathrm{pm}$, at least 15 hours per week of free access).

- Selection and support of webscouts.

- Co-ordination with parents association ('Schulverein') about the financial organization (payment for webscouts, ongoing costs).

The 25 winners had to sign a contract (another new experience) in which these criteria were laid down. After signing the schools received the following services and infrastructure resources from the project partners:

- The selected room was refurbished, painted and attractively renovated.

- A high value technical infrastructure (15 PCs, a laptop, peripherals, T1 Internet connection line and a LAN) was provided in each school.

- The webscouts were trained on 2-day training schemes and received a certificate after the successful completion of the course.

- The parents association received funding to pay the webscouts and other personnel to support the external users and finance ongoing costs.

- Co-ordination and support from the project management team at the University of Bremen.

Technical support is provided by a student organization. For the first two years, students of different faculties (but mainly from Computer Science) have helped schools with their technical problems. They have set up a help desk with a call center and a web-based FAQ-list. Additionally, they have worked on-site in schools. After several months of intrinsic motivation the district has taken over the financing of the project. Today, the project is a non-profit organization, is completely self-organized and employs 15 students and 5 technical experts. The School-Support-Service (S3) is working in more than 50 per cent of the 160 schools in Bremen. For the webpoints, they developed a reference installation for the complex case of double usage: teachers and students in the morning, external users in the afternoon. For students in computer science, this project offers more than a basis for living - directed by university lecturers, they build their own structures and processes, learn how to deal with difficult clients (teachers) and get additional technical know-how.

The first year of implementation of the webpoints revealed a lot of problems, especially in regard to construction sites and refurbishing and the co-operation with district officials about the network infrastructure. Additionally, some schools had difficulties in finding external partners to cooperate with. Schools with a long tradition of community integration experienced no problems - others did not even know whom to contact! On the other hand, after finishing the sites, the response from the local community was overwhelming. In many webpoints, senior citizens took the 
opportunity to learn how to use the Internet and lost some of their fears. This was the biggest advantage of the project had over other public Internet access points because the webscouts could give help. Effects of increased communication between the different age groups are difficult to measure, but site visits and qualitative interviews show impressive results. It appears both webscouts and external users have profited from each other. Apart from the very strong user group of senior citizens, the sites also offered additional courses:

- Reserved surfing hours for women, girls and families.

- Webscout courses for administrative personnel and cleaning staff.

- Theme days (Job-Fairs, video and music groups).

- Courses for disadvantaged groups (students, adults with special needs).

- Joint projects with community interest groups (city information systems, migration information system).

In summary, a threefold co-operation network could be created between:

- Schools and local community,

- Webscouts and external users,

- Schools and university (students, teachers, webscouts).

\section{REGIONAL EDUCATION NETWORKS}

In order to establish the webpoints as another form of public access points, it is necessary to embed them into the regional education infrastructure. The integration of computers as digital media requires complex coordination between all levels of the school system, making the separation between state and district affairs obsolete. The school district is the key regional player for this innovation process. This had already been stated in the late 70 s during the large-scale evaluations of the new U.S. federal education policy reforms - "In short, the groundwork and planning for sustaining a change agent project had the early, active, and continued attention of school district managers" (Berman and McLaughlin 1978). Furthermore, no innovation in schools can be successfully implemented without the principal. The results of several studies in Germany (Prasse and Scholl 2001) confirm our early findings in respect of digital media that "The principal was the key to both implementation and continuation".

From the perspective of a district or a county that wants to offer all people the chance to learn to handle the new digital media, the strategic approach adopted in the school system is not effective. It neglects the fact that only 10 per cent of the population are in schools. In order to achieve economic and social goals for structural change from the industrial to the information society, the institutions of adult education are of equal 
importance. If life-long-learning is more than a shallow term in politics, media literacy has to be relevant in all institutions of the education system. To solve these questions, the institutional framework of the school system has to be reformed. Other public or private institutions have to be involved. This will only succeed if the political will (leadership) exists and concrete incentives are available. To date, there are no experiences with, or detailed studies of, these cross-institutional approaches. There is also a lack of evaluation criteria on how to measure the trans-organizational learning process. This situation is typical for innovations. In all larger institutions, several innovation processes are run in parallel but all at different phases. Implementation will take time. The webpoints project proved that the innovation is worthwhile.

\section{REFERENCES}

Bertelsmann-Foundation (Ed.) (1997) Integrating Media into the Curriculum: Lessons from Athens Academy, Verlag Bertelsmann Stiftung, Gütersloh.

Brynjolfsson, E. and Hitt, L. (1996) Paradox Lost? Firm-level Evidence of the Returns of Information Systems Spending. In Management Science, 42 (4), pp. 514-558.

Berman, P. and McLaughlin, M. (1978) Federal programs supporting educational change, Vol. VIII. Implementing and sustaining innovations, RAND Co., Santa Monica, CA.

Baskerville, R. and Wood-Harper, A. T (1998) Diversity in Information Systems Action Research Methods. European Journal of Information Systems, 7, pp. 90-107.

Glennan, T. K. \& Melmed, A. A. (1996) Fostering the Use of Educational Technology: Elements of a National Strategy. RAND Corporation, Santa Monica, CA.

Kulik, J. A. (1994) Meta-analytic studies of findings on computer-based instruction. In Technology Assessment in Education and Training, E. L. Baker and H. E. O'Neill (eds.), Lawrence Erlbaum, Hillsdale, NJ. pp. 9-34.

North Central Regional Education Laboratory (1997) Developing a Plan for Learning through Technology, Illinois State Board of Education, Center for Learning Technologies, Illinois.

Nolan, R. L. (1993) The Stages Theory: A Framework for IT Adoption and Organizational Learning, Harvard Business School, Cambridge, Ma.

Prasse, D. and Scholl, W. (2001) Wie funktioniert die Interneteinführung an Schulen? In Das Internet und die Schulen: bisherige Erfahrungen und Perspektiven für die Zukunft, $\mathrm{R}$. Groner and M. Dubi (eds.), Huber, Bern, pp. 63-83.

Rapoport, R.N. (1970) Three Dilemmas in Action Research. In Human Relations, (23:4), pp. 499-513.

TNS-Emnid (2001) Der Verweigereratlas. Initiative D21 und TNS Emnid, Basiserhebung.

Wenglinsky, H. (1998) Does it compute? The relationship between educational technology and student achievement in Mathematics. Policy Information Centre. Education Testing Service, Princeton, NJ. 